\title{
An Interview with E. V. Ramakrishnan
}

K. M. SHERRIF

E. V. Ramakrishnan (hereafter EVR) is presently Professor Emeritus at Central University of Gujarat, Gandhinagar, Gujarat. He has published poetry and literary criticism, in Malayalam and English namely Being Elsewhere in Myself (1980), A Python in a Snake Park (1994), and Terms of Seeing: New and Selected Poems (2006), Indigenous Imaginaries: Literature, Region, Modernity (2017), Locating Indian Literature: Texts, Traditions and Translations (2011) and Making It New: Modernism in Malayalam, Marathi and Hindi Poetry (1995).

K. M. Sherrif (hereafter KMS) is Associate Professor and Head, Department of English, University of Calicut, Kerala. Among his better known works are Ekalavyas with Thumbs, the first English translation of Gujarati Dalit writing, and Kunhupaathumma's Tryst with Destiny, the first study of Vaikom Muhammed Basheer's fiction in English.

KMS: As a teacher who has worked among different linguistic communities, literary critic, bilingual writer and multilingual literary translator all rolled into one how you do look at the possibilities in translation among Indian languages and from Indian languages into English and foreign languages?

EVR: We are yet to comprehend the potential of translation between Indian languages in its totality. Apart from literature, there are several other resources in each language that need to be carried across languages. Unfortunately, in the postIndependent period, political boundaries have come to define the cultural boundaries in India. The minor languages within a linguistic territory and the bilingual communities across linguistic boundaries have come to be marginalized. Recently I read about the three tribal languages that are spoken in 


\section{K. M. Sherrif}

Attappadi tribal belt. None of the teachers in the Malayalam medium schools there speaks or understands these languages. Thanks to a concerned lady- teacher's efforts, the problems faced by tribal students have been noticed by the administration and society. They have appointed 'translators' to help students. I have taught in South Gujarat, which has a large tribal population. While interacting with tribal students there I came to understand that their mother tongues are not Gujarati or Marathi but local languages, which are not understood by the majority. Professor Ganesh Devy has done considerable work to promote tribal languages. Bhagavan Das Patel's translation of Bhili Mahabharat is a major contribution towards understanding our oral heritage. Translators have to reach out to minor and marginalized languages and also build bridges between communities speaking marginalized languages and mainstream languages. In a couple of generations, most of these languages may be extinct.

KMS: Three decades ago, Sujit Mukherjee described Indian literature in English Translation as a link literature for India. Was it a tenable argument in his time? Has the situation changed?

EVR: His point is well taken. Hindi has failed to evolve as a link language though it had the advantage of numbers, compared to other languages. English has emerged as a language of power with its vast resources in terms of global reach, command of technology and business. Indian writing in English scaled heights unthinkable in the $1950 \mathrm{~s}$ or $60 \mathrm{~s}$ in subsequent decades. All this has redefined the equations of power between languages within India. Literature produced in Indian languages has found international audience through translation in English. O. V. Vijayan or Anantha Murthy may not be as much known as Salman Rushdie or Arundhati Roy, but discerning readers in Europe and America have access to 
their works, thanks to global editions of their translations. Fiction and poetry from Indian languages have circulated widely through translation in English. While fiction has the advantage of big publishers and attractive literary prizes, poetry seeps through many boundaries to infiltrate cultural spaces. A recent translation of Urdu ghazals into English by Anisur Rahman has been a best-seller. In literary festivals across India and abroad, writers from Indian languages are attracting attention of readers through translations. I would say English has become a mediator, interpreting India for an international audience which includes a new generation of Indians who do not 'read' any Indian language.

KMS: Do you think the classification "Indian Literatures" a little fuzzy? There is a larger perspective of the Indian subcontinent as a cultural area, which would include countries or territories, which speak languages other than what is spoken in the political unit called "India" There is a presence of writers and artists from the SAARC countries, besides Afghanistan in major cultural events in India. Amateur organizations devoted to translation of literature include languages like Dari and Pashto also in their translation projects.

EVR: 'Indian Literature' as a category was constituted in the singular during the Orientalist phase of colonial period. In the post-Independence period, the nation-state uses its integrationist ideology to justify its unitary orientation. In reality, Indian literature is an eco-system of vast cultural imagination that includes multiple traditions from the oral to the written, from the tribal to the metropolitan, from the folk to the scriptural and from elitist to the subaltern. Unless we keep an eye on this vast diversity, we may idealize 'Indian Literature' to an imaginary universal status that will erase the lived realties it embodies. India shares many languages with its 


\section{K. M. Sherrif}

neighbours, and let us remember that South Asia is home to more than a quarter of the total languages of the world. Sanskrit and Tamil both of which have literary traditions going back to the era before Christ have preserved their works of great antiquity till today. The world is fascinated by this heritage and we have every reason to feel happy about its great worth. Tamil, Punjabi, Bengali, Urdu, Hindi, Telugu and Malayalam are spoken by large number of expatriates that constitute the Indian diaspora in present day's globalized world. Recently I met an Afghan student studying in Maulana Azad National Urdu University at Hyderabad. He was critical of the visibility accorded to the works of English works by Afghan authors at the total exclusion of Afghan writing in Afghanistan-based languages. There are several cultural markers that unify South Asia and we need to look into the linkages between languages and cultures across the region from Afghanistan to Cambodia. Comparative Literature Association of India (CLAI) has devoted some of its recent international conferences to South Asian Literatures and Cultures and the response from neighbouring countries has been good.

KMS: Has the role of the media been a promising factor in translation in India?

EVR: Visual media in English pay attention only to celebrities. They will highlight an author or a book when the book wins international acclaim. Or when an author is victimized as the case of Perumal Murugan illustrates. There are a few who understand the dynamics of regional literatures and their traditions among the English print media journalists. I remember how Times Weekly from Mumbai edited by Dileep Pedgaonkar (it ceased publication long ago and Pedgaonkar is no more) brought out a special issue on Marathi Dalit Writers in the mid-1970s. The Illustrated Weeekly of 
India serialized Samskara making it the first major successful modern Indian novel translated in English. Many political commentators who write in national media are bilinguals who are aware of the literary culture of the Indian languages. What is singularly missing is a national literary magazine that can showcase the best that is written and thought in Indian languages. Indian Literature by Sahitya Akademi is a bimonthly, which can hardly cope with the varied and prolific literary productions of India. The real constraint lies in getting good translations of major works. We have not paid attention to the teaching of translation in our curriculum. A language like Turkish is much smaller than Malayalam or Marathi but it has excellent translators. A writer like Pamuk got Nobel Prize mainly because Turkish has a translation culture that goes back centuries. At the Bogicazi University in Istanbul, I found that the Translation Studies department has more than fifty faculty members. They publish a world-class journal in translation. In Italy, I am told, (I have not verified this) there is an entire University only for Translation Studies. Every language department in our colleges and universities need to incorporate a component of Translation Studies. We need at least a couple of Universities in each state with Departments of Translation Studies. It will greatly help disciplines like Media Studies, Theatre Studies, Film Studies and Culture Studies not to mention Comparative Literature Studies.

KMS: How do you look at author translation? Has it proved effective in translation from Indian languages? Or has it run into issues of appropriation and manipulation?

EVR: Self-translation has a tendency to rewrite the original. This can 'corrupt' and misrepresent the text. This has happened with the best self-translations. O. V. Vijayan is a good example. Issues of appropriation and manipulation can be brought out only through close readings of translated texts. 


\section{K. M. Sherrif}

Unfortunately, we are yet to have Translation Studies as a major programme in our universities. Readers fail to distinguish between translations by authors and other professionally trained translators. The remedy is better theoretically-sound detailed studies on translations as a cultural process.

KMS: What role do you foresee for digital technology in translation? The limitations of computer aided translation or machine translation has already been acknowledged both by the academia and by the techies in the field. Yet, translation memory as a growing corpus, which accretes with translators working online, appears to be quite promising. What are the indications?

EVR: Digital translation has progressed much and it can take care of several public requirements of listings and documentations etc. However, when it comes to creative writing or texts with dense intellectual arguments, machines will not be of much help. Maybe artificial intelligence will keep making progress and take over some of the functions of translation. But I feel strongly that the inventiveness of language cannot be matched by any digital technology. Yes, translation memory as a growing corpus can be enabling. It will enlarge the choices available for the translators. For instance, when you translate from a dialect of Hindi or Malayalam, the English equivalents are hard to come by. It may be helpful to have resources for such contexts of translations. Words and registers dealing with specific profession or life experience may also have to be expanded slowly though accretion. Digital humanities should address problems of translation as well.

KMS: How promising are translations between Indian languages as opposed to translations from Indian languages into English? 
EVR: Unfortunately, Indian languages drifted apart in the post-colonial period due to their politics of culture. Despite there being several Tamil-knowing scholars in Malayalam, how many good translators have we produced in that language? From Hindi or Bengali we have been translating into Malayalam for a long time. Even here, the number of good translators is dwindling. On the other hand, there is greater demand for international best sellers and award-winning English authors. This has created a good market for translations from English. However, there is another side to this issue. Translations do not occur in a vacuum. Whenever the literary sensibility reinvents itself or the hegemony of prevailing aesthetics and ideology is challenged from the margins, as in Dalit writing or Women's writing, the pace of translation accelerates and it is an indicator of cultural transformation. Dalit writers from Marathi got translated into Hindi in the 1980s as part of the Dalit movement in the Hindi belt. Women's writing in Malayalam also was greatly enabled by translations from Indian as well as foreign authors. If there is a genuinely original voice in any Indian language, it will soon be translated into other Indian languages. The growing popularity of translators at Literary Festivals is an indication that Indian writers have more opportunities now to meet and listen to regional writers from other languages.

KMS: Two of your books, Making it New and Locating Indian Literature offer highly motivating insights into parallel instances of canonization, emergence of literary movements and linkages between literary and political movements in Indian literatures. How do you look at the role of translators in facilitating comparative literary studies involving Indian literatures?

EVR: I could undertake these studies because good translations of representative writers of the modernist 


\section{K. M. Sherrif}

movement were accessible. My understanding of these languages also helped. Translations are essential for comparative literature studies to flourish. We know that it was migration of European scholars to the U.S. during the 1940s that paved the way for the emergence of Comparative Literature Studies in American universities. In a world where migration has increased many folds, translation is essential to make sense of reality. There is evidence to suggest that the othering of certain countries and communities is the result of inadequate understanding of their cultures and traditions. Translators give access not to a mere text, but a whole culture. Subtitles in films, write-ups on foreign authors and new titles, commentaries or accounts of cultural events, interviews with authors from other countries etc are also modes of translations that have gained currency. I have used interviews with authors in my book, Making It New as a means of accessing their creative worlds. Theoretical writing in Indian languages often use of concepts of western theory in translated form. Ideas of Marx, Freud, Gramsci etc got disseminated in India through academic writing that has strong content of translation. The fact is translation exists in many forms in contemporary culture. When an Iranian film director is interviewed by a Malayalam weekly that is translation.

KMS: What kind of translation would you advocate between Indian languages? Domesticating? Foreignizing? Of course one has to apply slightly different yardsticks than what Lawrence Venuti employed when he formulated his domestication-foreignization binary. Is building bridges a more important criterion than offering highly readable texts?

EVR: You are right in saying that it is a binary that may not be totally relevant to us. For instance, between Tamil and Malayalam, one can use a mode of translation that is readerfriendly and author-friendly at the same time. This question 
becomes relevant when Indian language texts get translated into English. English translations insist on 'fluency' as a quality and this forces the translator to make translation domesticating. However, there are core issues in a text that need to be retained in a translation either by using words in the original or retaining the tone of the original. English tends to universalize experiences erasing the local and the regional. This can be an act of cultural violence in the context of translation. We need more studies of translations between English and Indian languages.

KMS: It has been observed that Translation Studies is one of the weakest branches of literary study in all Indian literatures. Europe or America does not have the history that translation has had in the Indian subcontinent over the last two millennia or more. Yet few studies have offered discussion, either theoretical or descriptive, on them. In contrast, Translation Studies has taken big strides in countries like Belgium and Israel with populations of just a few million. Although seeking to fashion home-grown theoretical paradigms on translation in India may be justified, wouldn't it be resourceful to use Western translation theory also to study translation in India?

EVR: Translation is basic to the constitution of the category called "Indian Literature". Around 1000 A.D. modern Indian languages from Assamese to Telugu made a transition from being mere spoken languages to literary languages through the creation of powerful literary texts, and all these literary texts were translations from Sanskrit. We have never studied this phenomenon with the seriousness it deserves. In Malayalam, from Ramacharitam to Nalacharitam, all the major works are translations from Sanskrit puranas and epics. Of course, there are oral traditions which are local and indigenous. Even they use translations in different ways. These acts of translations were attempts to negotiate power relations between the 


\section{K. M. Sherrif}

local/indigenous and the universal/pan-Indian. We need a vigorous discipline of Translation Studies to explicate and analyse the complex ways in which texts were constituted in Indian translation traditions. From Parsi Theatre to modernist theatre, much of modern Indian drama freely borrowed themes, styles and modes from foreign traditions, often masking their sources. We need to devise new theoretical categories while studying these phenomena. The compulsion to theorize translation was absent for two reasons: it was native to the literary traditions of 'vernacular' imagination and secondly, writers who practiced translation were not self-conscious about it. Theorizing begins when we step out of the frame and reflect on the process from an outsider's perspective. This was not available to Indian scene till colonial modernity made its appearance. Yes, we need to borrow insights from theories already in circulation. Your examples of Belgium and Israel are very relevant. I cited the example of Turkey. Latin American scholars have come up with the idea of translation as cannibalism. Maybe, we can talk of translation as 'parakayapravesam' or 'reincarnation'? In fact, the large numbers of terms we have for translation, such as 'anuvad', 'paribhasha', 'tarjama', 'mozhimattam', 'vivarthanam' etc. carry the seeds of theory, which can be developed.

KMS: Do you consider creative writers the best translators of literature? Have translations in India generally offered evidence for this? Can one consider translation creative writing? Is the translator a 'secondary creative writer'?

EVR: I have often felt that poets make good translation of poetry. But even here, I would argue that translation needs as much creativity as original writing and cannot be considered a second-rate cultural activity. A. K. Ramanujan's translations of ancient Tamil or medieval Kannada poems mark a breakthrough in the history of translation of Indian poetry but 
they have been criticized for falling into a trap. Hence, translations need to be constantly evaluated and discussed. Classics will require multiple translations. Tagore's Gitanjali has had more than twenty translations in Malayalam and also in Gujarati, but each translation captures some facets of the original which were missing in earlier translations. Tagore's own translation of his poems has been severely criticized for what they make of the original. Translation is as much a critical activity as a creative act. Recently I translated a series of poems that speak of freedom and justice, into Malayalam, and it was as painstaking as composing original poems. The important thing is it satisfied something deep in me. In that sense, it was a creative act.

KMS: How effective have been the efforts of the Sahitya Akademi and National Book Trust to bridge the languages and literatures in India through translation?

EVR: I have been a member of the Advisory Board of the Sahitya Akademi for English for two terms. I know how difficult it is to locate good translators. Both the Akademi and NBT have a list of translators and they do make every effort to translate the best works of each language. But, somewhere along the line, they fall behind the private publishers in bringing out the best translations of reputed works. The questions of meticulous editing and commitment to the cultural role of translation are not sufficiently understood by these state bodies. They also have to pay translators better if they are to get the best translators. An OUP edition of translation goes through many stages of scrutiny that ensures quality. No such painstaking editing is visible in Sahitya Akademi or NBT translation projects.

KMS: Do you think the syllabi in universities and colleges in India have given sufficient representation to Indian Writing in 


\section{K. M. Sherrif}

Translation, whether into English or other Indian languages? Is a paradigm shift necessary?

EVR: I was recently a resource person in a University where they were trying to introduce regional writing in English translation. The selections were good but the larger objectives of the syllabus were vague. The act of translation was never addressed as part of the syllabus. The undergraduate classroom should be the space for creating awareness about the complexity of the process of translation as a cultural activity. This can be done using short films or interviews or subtitles in films or reading the original followed by translation. Translation cannot be taught. It is a collaborative activity. Hence it demands a workshop model of participation and sharing. How many teachers will be able to lead such activities? Finally, when we teach a story in translation, attention is not on how 'translation' as a process constituted the text, but as a story in English. Our examination system focuses on objective skills where mastery of skills of translation are not seen as desirable goals. This needs to change. A graduate has to possess some basic skills of translation into English or some other Indian language.

KMS: Masterpieces of Indian Literature is a monumental work which introduces works in India's literatures to readers in English in India and abroad. Do you think a more contemporary compilation is now necessary - especially in view of the fact that more literatures like Bodo, which have not been accessed in the book, are now being translated profusely into English and other Indian languages? There have also been noticeable changes in the ways in which literature is read and discussed.

EVR: Yes, we need a revised version of many such compilations. In Indian literatures, the possibilities are endless. Once, Dilip Chitre and I discussed how we could edit a series 
of anthologies of Indian poems on such themes as love, death, travel, memory, dreams etc. We need several such anthologies. We also need intellectual biographies of authors, biographical dictionaries, dictionaries on cultural phenomena that have shaped texts etc. Instead of writing a dissertation a candidate can either translate a text with a critical introduction or write an intellectual biography of an author which can be considered equivalent to a thesis. Such innovative approaches are part of research in many foreign universities. In order to read Perugmal Murugan or Sarah Joseph we need to know several things about religion and rituals in India. Where do we seek them?

KMS: Movements and trends like Progressive Literature, Dalit Writing and Women's Writing have made indelible marks in many literatures in India. Often the same movement or trend appears in different forms and with different levels of intensity in different literatures. As a writer who has documented such movements in India's literatures, do you think such documentation has kept pace with the appearance of such movements and trends? Do you think a more comprehensive and precise recording of literary history is necessary to account for such movements and trends, and more sensitive translations to take it across to other literatures?

EVR: We have not kept pace with the changing nature of such cultural phenomena. For instance, we hardly have any idea about the environmental movements in Hindi or Marathi though I have come across many works in these languages dealing with such issues. As you said above, languages like Bodo and Santhali have an altogether different take on ecological issues as they have rich oral traditions. We have not even documented their literary traditions going back to many centuries. Trends have a tendency to move across Indian languages through creative osmosis. This has not been studied 


\section{K. M. Sherrif}

in detail. We tend to follow the West in tracking literary movements. Hence, we insist on finding a post-modern phase here, though our 'modernist' phase is yet to be defined. In finding synonyms for Romanticism, Modernism, Postmodernism etc. we have not bothered about their contents. Is there an Indian way of being romantic or modernist? That will raise many issues. Nirmal Verma or Puthumaiputhan are not modernists in the same manner.

KMS: Can we think of more vigorous student-exchange programmes in universities and states across linguistic communities to facilitate more prolific and sensitive translations between Indian literatures?

EVR: That is the way we should move forward bringing multiple traditions face to face. Translation can flourish only in an atmosphre of difference and a context of relating to the other. Students who are capable of speaking more than one or two languages should be encouraged to take up translation. There should be occasions where successful translators meet them and introduce them to the craft and art of translation.

KMS: Works like Harish Trivedi's Colonial Transactions try to look at the interface between Western and Indian literatures. It is undeniable that without this interface few literatures in India would have developed the way they have. Do you think this interface has been given its due in critical writings in Indian literatures?

EVR: This interface has not been sufficiently understood by us. Recently I have been working on literary historiography and I found that none of the literary histories in Indian languages ever take translations seriously. From late $19^{\text {th }}$ century, new literary forms such as the novel, the short story, autobiography, travelogue etc made their appearance through a series of translations. But we fail to document the process that resulted in the production of the massive cultural 
transformation. There are several trajectories that need to be mapped in detail to get a comprehensive view of Indian literary transitions. Anantha Murthy wrote his Samkara while in England. Nirmal Verma, the Hindi novelist, spent ten long years in Prague and when he came back to India he was deeply disillusioned with communist ideology. Something similar happened to O. V. Vijayan when he was writing the novel, The Legends of Khasack. The relations between India and the West need to be understood not in terms of master and servant, but in the context of reception. It is the dynamics of Indian sociocultural context that decides what will be received or rejected. Influence studies have to give way to reception studies, and here let us underline that translation is an important mode of reception.

KMS: Jawaharlal's designation of English as India's window to the world was realized in several ways. One of them was the entry of texts from languages other than English indirectly through English translation. In Malayalam for instance, almost all translations from Russian and French (there are quite a few) before 1947 came through English. Indirect translations continue to arrive in Indian literatures through English. What are the good, bad and ugly of this process?

EVR: I think this process has something to do with the colonial context of our history which cannot be wished away. The British hegemony ensured large-scale dissemination of English in the subcontinent. It was inevitable that it cannot be dismantled over a few decades, despite the strong decolonising impetus that drove our politics. We continue to access other literatures of the world through English translations. This is true of many cultures in Eastern Europe just as Spanish has become the language of South American countries. Many African countries use French for the same reason. The best part of this scene is that we have a tradition of teaching English in 


\section{K. M. Sherrif}

this country which makes it accessible to large number of people. The bad or ugly side of it is that English translations carry their own cultural baggage and we are often unaware of it. An author like Paulo Coelho has nothing to offer to Indian audiences but he is sold in millions even when translated into Indian languages. A lot of cultural garbage is marketed very successfully by the efficient system of global capitalism which promotes English. Translation Studies along with Cultural Studies have a crucial role in shaping the process of reception as a critical activity by providing informed criticism.

KMS: The National Translation Mission's efforts to translate knowledge texts in English and foreign languages into English constitute a huge translation project. How do you look at the project in terms of its impact on India's linguistic communities?

EVR: I am aware that it is a major project, which will make the Indian knowledge system available to a larger audience. For instance, we have hardly any translations of literary criticism in Indian languages into English. It is important to take stock of our achievements in our thought systems and the manner in which we have devised our critical vocabulary or discourse. I am sure it will alter the way in which we view Indian languages and their knowledge systems.

KMS: The National Translation Mission has consistently given proportional representation to regions and languages in India in its workshops and other programmes. Have other national or regional organizations followed this model?

EVR: NTM has followed an inclusive policy in organising workshops and seminars etc. In a vast country like India, there is acute shortage of resources when it comes to organizing programmes of this kind. I strongly feel regional and local initiatives in organizing translation workshops or seminars with one or two resource persons from outside are still a viable 
idea. I have been part of many such programmes in many parts of the country. At the same time, we are lucky to have an institution like CIIL where NTM is located. They are able to bring together experts from all over the country to meet and discuss important issues related to Translation Studies in India. We should ensure that their publications have greater circulation to create an impact on the higher education system.

$* * *$

\section{Cite this Work:}

SHERRIF, K. M. 2020. An Interview with E. V. Ramakrishnan. Translation Today, Vol. 14(2). 157-173. DOI:10.46623/tt/2020.14.2.in1 